\title{
The Role of Community Leaders and Other Information Intermediaries During the COVID-19 Pandemic: Insights from the Multicultural Sector
}

\section{Holly Seale ( $\sim$ h.seale@unsw.edu.au )}

University of New South Wales https://orcid.org/0000-0002-1877-5395

\section{Ben Harris-Roxas}

University of New South Wales

\section{Anita Heywood}

University of New South Wales

Ikram Abdi

National Centre for Immunisation Research and Surveillance

Abela Mahimbo

University of Technology Sydney

\section{Ashfaq Chauhan}

Macquarie University

\section{Lisa Woodland}

NSW Multicultural Health Communication Service

\section{Article}

Keywords:

Posted Date: February 18th, 2022

DOI: https://doi.org/10.21203/rs.3.rs-1360132/v1

License: (9) (i) This work is licensed under a Creative Commons Attribution 4.0 International License.

Read Full License

Version of Record: A version of this preprint was published at Humanities \& Social Sciences

Communications on May 17th, 2022. See the published version at https://doi.org/10.1057/s41599-022-

01196-3. 


\section{Abstract}

Community and religious leaders, as well as other natural leaders, from culturally and linguistically diverse (CaLD) backgrounds have been posited as a gateway into communities, acting as information intermediaries that enabler or broker public health messages about the COVID-19 pandemic. However, there are currently limitations regarding our understanding of the capacity, role and reach of these leaders. In-depth interviews were undertaken to understand the perceptions of those working in services and other social support roles focused on CaLD communities towards the role and impact of information intermediaries in promoting and supporting COVID-19 public health communication and engagement activities.

Forty-six semi-structured telephone interviews were undertaken with key stakeholders who have an active role in the delivery of services and other social support to CaLD communities in Australia. Four key themes emerged related to the role of information intermediaries during the interviews. Ideas around the role they fulfil in "bridging the gap" and supporting the delivery of pandemic related information into communities. Participants suggested that there had been a failure by Federal government agencies to recognise the role of these stakeholders early in the pandemic, as well as a failure to provide sufficient resources and support. However, concerns were also raised that information may be inappropriately interpreted or translated by the community information intermediaries or potentially blocked, if the message does not align with the broker's own beliefs. Finally, concerns were raised about the potential for burn-out amongst information intermediaries.

It is critical that in preparing and responding to pandemics and other disasters, that there is recognition of the role of community leaders and other information intermediaries and that resources are identified to enhance and sustain their involvement.

\section{Background}

Communication barriers can severely hamper access to, and use of, healthcare services by people from CaLD backgrounds, because of limited knowledge about services and/or limited understanding about recommendations (Henderson \& Kendall, 2011). Formalised responses to this issue by statutory and/or non-statutory agencies often include provision of translated health information, producing uncontextualized text-heavy resources and/or training health staff in cultural competency (Abdi, Murphy, \& Seale, 2020; Wild et al., 2020). The challenge is that these strategies can be limited in scope in that: (1) not all people from Culturally and Linguistically Diverse (CaLD) backgrounds have the required literacy and health literacy skills to read and understand the materials (even if written in their own language) (Jessup, Osborne, Beauchamp, Bourne, \& Buchbinder, 2017); and (2) having a translated resource does not necessarily mean that the messages are reaching the target audience nor are they meaningful for CaLD communities (Ogie \& Perez, 2020). 
Previously, Mileti and Darlington (1997) found that people from CaLD backgrounds generally prioritize social networks and interpersonal communication when seeking information and prefer to receive information from people with similar attributes as themselves (Mileti \& Darlington, 2014), which has been confirmed in a range of other settings (Tierney, 2019). This is especially true of cultural groups that are more collectivistic and cooperative, and who like to share their experiences and information with their community (Chen \& Choi, 2011). In settings like Australia, people from CaLD backgrounds often form tight-knit communities with strong internal linkages and these social networks (including relatives, friends, colleagues, neighbours) may act as sources of information regarding appropriate medical care (referred to as interpersonal communication) (Cohen, Brissette, Skoner, \& Doyle, 2000). Traditionally, a large amount of interpersonal communication occurs within community networks that are physically local. However, over time this has shifted to include online networks via short messaging apps like WhatsApp and WeChat, and online platforms that allow closed and semi-private groups such as Facebook.

Within these social networks, there can be individuals that are purported to play an enhanced role in transmitting information within their community. 'Gatekeeper' is a term that has been previously used to describe people in the community who are able to facilitate other people's information and/or help seeking behaviours. Borrowing from attachment theory, the gatekeeper model posits that individuals may find comfort sharing their feelings with acquaintances (Anderson, Maile, \& Fisher, 2010). The model is also influenced by the public health principle of mass saturation of awareness, whereby the likelihood of community members intervening in a crisis increases with the proportion of capable gatekeepers (Lipson, Speer, Brunwasser, Hahn, \& Eisenberg, 2014). Originating out of the US in the 1970's, the model focused on the training of non-professionals including mail carriers and hairdressers to identify older adults with health (mental health or suicide prevention) or social issues and to refer them to formal service providers (Keith, Jeffrey, \& Lynette). It is built on the notion that these informal social exchanges occur more frequently and hence the gatekeeper can identify any issues (Florio \& Raschko, 1998; Sarason, Sarason, Shearin, \& Pierce, 1987). In this current study, we acknowledge that gatekeepers may be the CEO of community organisations, community or faith-based leaders or 'natural' leaders (example: a person who has completed medical training but does not practice in Australia). In this paper, we recognize gatekeepers as people who are linking others to information, and so feel that the more accurate term could be community networker or information broker.

Australia's COVID-19 Vaccination Program Culturally and Linguistically Diverse Communities Implementation Plan (Australian Goverment, 2021) lists "community leaders and young people, and multicultural organisations as the gateway" to support information delivery. Given the acknowledged role of these community leaders in the government's strategy, this project aimed to understand the perceptions of those working in services and other social support roles focused on CaLD communities towards the role and impact of community, religious and other leaders in acting as information intermediaries to support COVID-19 public health communication and engagement activities.

\section{Methods}


Semi-structured in-depth phone interviews were undertaken with key stakeholders and informants, of approximately 30-40 minutes in duration, between January 2021 and April 2021. The focus was on CaLD communities that include people who were born in non-English speaking countries and/or English is not the main language spoken at home. [11]. The Human Research Ethics Advisory Panel at the University of New South Wales reviewed and approved this study.

\section{Sampling}

Key informants were defined as those people who have an active role in the delivery of services via multicultural health and other social support via migrant resource centres, refugee health services, settlement services, community-based organisations, translation services and primary care settings. Stakeholders were those people who play a role in multicultural health and diversity related activities whether that be through advocacy, policy/program development or research. This principally encompassed personnel such those from government agencies or CaLD community peak bodies/Councils, and CEOs from community groups.

This study used a range of national-local-personal approaches to recruit participants. Firstly, an online search of relevant websites was conducted to identify potential candidates matching the selection description. Each candidate was then followed up via email with an invitation letter. Secondly, interested candidates were asked to directly recommend any colleagues who may be willing to participate. Lastly, we sent emails directly to known relevant contacts of the research team who were working in the relevant sectors. An effort was made to recruit at least one participant from each of Australia's states and territories to capture a broad range of views on issues affecting the country. However, we were unable to recruit any participants from the Northern Territory. Participants were only included in the study when full verbal consent had been received. This study did not collect any identifiable personal information from the participants.

\section{Data collection and analysis}

An interview guide was developed and reviewed by the researchers ( $H S, B H R, A H, I A, A M)$ to identify key areas of interest for the study. The questions related to the following topics: perspectives towards the current communication approaches being used by the government, factors affecting on communication and engagement with CaLD communities, the communication roles and influences of different agencies, and suggested options that could be adopted to enhance communication and engagement around the COVID-19 vaccine program. Questions were asked in an open-ended manner to allow room for expansion (Richards, 2014). During the interviews, member checking was conducted to ensure that the ideas identified during the early phase of analysis were appropriate. The data were analysed using thematic methods of building codes into themes using the constant comparison approach by HS and AC using NVivo software. Themes were compared within and across the sample and structured around the key interview topics while also allowing inductive and cross-cutting themes to emerge from the interview data. Any differences between the coders were resolved via discussions with the wider team to ensure vigorous analysis. 


\section{Results}

Forty-six interviews were undertaken with key stakeholders and informants across Australia. The characteristics of the participants and the interviews are described in Appendix 1 using the CORE-Q reporting format (Tong, Sainsbury, \& Craig, 2007). The themes identified that apply to community leaders and information intermediaries and are described in the text below.

\section{Important role in bridging the gap}

Across all the interviews, the perceived important role of community information intermediaries including community leaders, religious leaders, and other 'natural' leaders was raised. Participants often referenced the role of community leaders and other information intermediaries have had in promoting other public health initiatives in international settings. In the Australian setting, they associated the term 'information intermediaries' to include community leaders, faith-based leaders, natural leaders, bilingual workers/case or settlement workers, youth leaders, bilingual health professionals, local council members, and translators/interpreters. It was also suggested that community members who have health backgrounds (medicine, nursing, pharmacy etc.) but who are not registered to practice in Australia could be considered as community ambassadors, given their ability to interpret and synthesis the information about COVID19. Participants suggested that within communities, there are different people who play a role in providing information and that community members may "go to different people for information".

The need to identify and work with local community information intermediaries was recognized as being instrumental to bridging the divide with the community and to ensure that information reaches all community members. It was suggested that these people understand their communities and have good networks and links into the community.

"One of the first outbreaks I think in our region was in the meatworks, and most of the employees at the meatworks work from Karen and Burmese heritage. A lot of people in those communities don't read or write in their own language as well, and so thanks to the local community leaders, we set up a testing site and most people heard of it from word of mouth". (Interview 24).

It was stressed that the role of these community leaders was not just about passing on COVID-19 information but in some settings, they also set up support networks, homework groups and Zoom sessions focused on a range of community-nominated topics including mental health, family violence, finances etc.

However, there were a few participants who questioned the role of community information intermediaries and whether these individuals had the necessary understanding to have any impact. In many situations community leadership is self-nominated, and these leaders may not have the necessary reach or relationships to support engagement. Some people stressed that they did not know if information was "filtering completely down". 
"One of the biggest challenges we have is, in fact, communicating with those community leaders. Sometimes their educational levels are questionable. When the government says, "Well, we've approached the community members," do you genuinely know whether that person is a fit for the purpose that you want? Are they going to deliver that information and are they delivering as you wished?" (Interview 13)

Participants also raised concerns that information may be inappropriately interpreted or translated by the community information intermediaries. Some may even block information from reaching communities. For example, issues were raised that some of these community ambassadors may hold their own concerns about COVID-19 vaccines and so would not be willing to pass on information. To circumvent this issue, participants spoke about using multiple channels to disseminate information including via the community leaders but also via public information sessions and other bicultural workers. This was particularly important for community groups presented by a range of dialects or languages including the Sudanese community.

"I think the whole community leader thing, it's very convenient because you offload the responsibility to someone. Who are these community leaders? They follow their own perceptions, their own way to see, do things. Yes, we obviously need connections to the community, but also, we need to be very aware how this is done. (Interview 42)

"There's no formal understanding of how well those people are going to then take notes and represent it." It's just an expectation that they are professionally qualified to deliver that. I'm almost certain that they are not professionally qualified to do that because they don't train to do that". (Interview 13)

"...some community leaders don't always act in their best interest because of power imbalances. They're worst, and thankfully this is not too common, but there are examples where it becomes a disservice because they try and block other channels of information for purposes of control and a whole bunch of complicated things". (Interview 44)

Amongst those participants who were supportive of the role of community leaders, was the sentiment that governments need to engage with them on an ongoing basis including for emergencies:

"on a permanent basis because it was COVID, now it's vaccines, but it could just as easily have been bushfires, flood, or famine, maybe not famine, but bush fires or floods, heat, extreme heat. There's any number of emergencies that continue to arise that we need to have good access to community members, through community leaders". (Interview 16).

\section{Failure to consult with community leaders}

Participants raised some criticism that the health departments did not recognise the importance of these information intermediaries until later stages of the pandemic.

"I asked the Health Minister how he engaged with the community, he said, "We're talking to community leaders of different cultural groups." I just thought, "That's really interesting. That's a shift." We weren't 
Eventually some of the health departments funded: "...community health centers to employ bicultural workers from their local communities for contact tracing, for upright management, and for general information". (Interview 16)

In the early stages of the pandemic, participants mentioned that they were concerned that very little consultation was occurring, however they did acknowledge that this improved during 2020 and 2021. However, participants continued to question whether governments were actively involving community leaders and other information intermediaries or whether they were just extracting information from them: "every time we need anything that has to do with CaLD, we go to the leaders and then we get the information that we want and then we forget about them. We don't even go back to tell them, this is the outcome of whatever we were doing is, and this is what we achieved." (Interview 6). One participant went as far as to suggest that the way governments interact with community leaders is not a new situation but a long-standing issue:

“... when we [the government] need you, we'll grab you and all the rest of the time, you don't matter, which is not right or fair" (Interview 16)

There has been a perceived failure to maintain good relationships with these leaders. It was stressed that there must be structure in place so that governments can support and engage with community leaders, to undertake more timely consultation and to check in with communities prior to messages being distributed. One suggestion was to have a standing committee in place. However, concerns were raised that governments often find it easy to deal with one community member and so assume "that the whole community thinks the same way", potentially disadvantaging some within the CaLD community.

Another issue raised was the fact that community leaders are not necessarily given the opportunity to contribute to the development of messages targeted at their communities but rather just given a script and put in front of a camera. In some settings, some community leaders may prefer this approach, but concerns were raised that this failure to involve the leader may contribute to audio and visual materials that don't necessary resonate with the target communities.

\section{Level of briefings and support}

Concerns were raised across many of the interviews regarding the training and support provided to community leaders and other information intermediaries. One participant questioned the level of guidance available to support, while others raised issues around how they were being briefed ("randomly") and whether the briefings (if they were occurring) were useful or successful in supporting the leaders to communicate correct information with their respective communities. It was suggested that it was "assumed" that the community leader was "up for it" (i.e., communicating about COVID-19) and that they may not have been prepared, which puts them at a compromised position. 
"The government tends to inform the professional public to then further inform their constituents, and customers... through media releases or through government policy documents. They're able to consume that, understand it, and then regurgitate it, so to speak. When I have a look at how the community leaders are being briefed, I can't see any guidance document to community members". (Interview 13)

Participants raised additional concerns about the level of support being given to community leaders (and other bilingual workers) in regional and remote areas. To fill this gap, one participant stated that they had created a community leaders forum, which included regular Zoom meetings with community leaders across a particular geographic area of Sydney to talk about the key COVID-19 issues. External experts or government representatives were invited to attend the session as well. The aim of these sessions was to help ensure the consistency of the information being distributed. These sessions also allowed community leaders to raise issues about government requirements and to advocate for changes/resources etc.

One participant highlighted that it was important to distinguish between training and supporting people. In this situation, community leaders are not being actively sent out but rather are being invited to "have conversations" with their communities. In this setting, the participant spoke about holding forums which provide opportunities for open and honest discussions about the pandemic. They mentioned that at the end of the forums they emphasized to attendees that "if [they] feel comfortable, we'd love for [them] to have more conversations in community". As these community leaders are volunteers, it is important to build their confidence to have conversations.

“We have to be careful because they (community leader) shouldn't be responsible for answering complicated questions, but if they have a better understanding, they can at least point people in the right direction". (Interview 45)

\section{Danger of 'burn out'}

One of the strongest issues that was raised was the issue of community leaders burning out. Participants highlighted that they had heard from the community leaders that they felt "overworked and overstressed" and that a huge responsibility had been put on them to get information out, with pressure coming from "both sides". They are asked to repeatedly translate, understand, synthesize ("government speak into community speak") and disseminate messages and answer questions. This role can come with an emotional burden. Amongst those interviewed, issues about a lack of acknowledgement of the contributions from community leaders and lack of payment were voiced. Participants highlighted that these community leaders were volunteering their time, on top of the other responsibilities (i.e. paid roles) they had.

"It's unpaid. It's unpaid work. It's really too much for them basically". (Interview 5)

"There is a danger of the fatigue of these ambassadors... Then the lesson learned has to be capacity building for the next time it happens and perhaps local governments having better connections with 
community, knowing who their different communities are, making sure that if we go into a lockdown situation" (Interview 45)

One idea put forward was to pay community leaders for their time, to acknowledge their contributions but also as an incentive to attend training. However, the capacity to provide this funding was questioned.

"My recommendation is to engage them in a professional capacity to pay for the work that they do, depends on the sessions. Maybe hourly rate, whatever. Just based on either per session or per hour or whatever it is to be able to deliver". (Interview 5)

While funding may not be feasible, at the very least governments need to do more to publicly recognise and show appreciation for the role that community leaders and other information intermediaries have had during this pandemic. Lastly, participants reflected on the lessons that need to be learnt from this experience including around capacity and relationship building so that when it happens next time, governments have better connections with the community, know who their different communities are and have the relevant contact points.

\section{Discussion}

Information intermediaries can be differentiated into those occupying informal and formal (institutionally affiliated), roles, aligning to whether they are nominated into the role or have emerged from a social position. Research on gatekeepers suggests that they: (1) tend to have relatively higher education or language literacy skills; (2) are well known and frequently involved in their communities and (3) are multilingual and multiliterate (Bozkurt \& Gürsakal, 2017; Lu, 2007). Currently assumptions are made that information delivered by community leaders, will circulate into their respective communities. But do we truly understand the mechanisms, whether information is accurate, or the types of influences applied? These are key concerns raised by our study participants about the dissemination of public health information about COVID-19 and about the promotion of the COVID-19 vaccination program.

Previous studies on the role of information intermediaries in the dissemination of messages has suggested that the past experiences, knowledge, length of stay in a country and level of self-efficacy can impact on the persons communication behaviours, especially around risk perception, information dissemination and filtering (Lu, 2007). Research has also found that communities in almost all settings identify strategic actors for the dissemination of information within groups (Agada, 1999; Buchanan, Jardine, \& Ruthven, 2019). Through influencing the flow of information, information intermediaries can potentially shape and inform their community's reality and knowledge. For example, during the 2011 Brisbane floods, they were found to have adapted information for CaLD communities by changing measurements from metric to imperial, making information "less scary", or filtering out information that was geographically irrelevant, or in some cases, not transmitting information at all (Shepherd \& van Vuuren, 2014). If information intermediaries are selectively filtering information during a pandemic situation, communities may not be receiving timely or accurate information regarding public health strategies such as the vaccination program. Reliability and trust are significant issues, as intermediaries 
can bridge gaps but in order to be effective, it is critical that they have the capacity to understand what the information needs are of the population they are serving, as well as the implications of moderating or withholding information (Buchanan et al., 2019).

Participants acknowledged the need to move beyond relying on already-recognised community and religious leaders, and to identify other possible community contacts. One key reason for this was to reduce the issue of 'burn out' amongst the community leaders, especially given the amount of work that some members put in during 2020. One possible suggestion was to enlist people from CaLD communities who have a medical background as vaccine champions. These include bilingual health staff and community members who may have trained as doctors, nurses or in other health areas but who are not licensed to practice in Australia. The idea being that these individuals are still valued within communities as having a medical education and understanding and so can help with disseminating information within communities in the community language.

The need to provide support and training to community gatekeepers has been well recognized in other public health and clinical sectors including gatekeepers as a strategy for identification and early intervention in the prevention of suicide (Isaac et al., 2009; Yonemoto, Kawashima, Endo, \& Yamada, 2019). The training is aimed at specific groups of people to assist them in developing the knowledge, attitudes, and skills, to identify people at high risk of suicide and to refer them on for treatment. Key components of the training focus on: (1) preparing (setting the tone/expectations)' (2) connecting (reflecting on one's own attitudes); (3) understanding (developing knowledge and skills to assist); (4) assisting (relevant strategies that can be used); and (5) networking (understanding local community resources and how to network) (Isaac et al., 2009). Similar programs have been rolled out to support gatekeepers with mental health care in adolescent and adult populations (Lipson et al., 2014). In supporting gatekeepers to have an effective role in support public health actions during a pandemic, training that adapts these five elements may be useful to enhance the understanding, skills, and confidence of community gatekeepers to talk or address questions about testing, or vaccination. As acknowledged by our participants, there may be varying levels of attitudes and views amongst community gatekeepers towards the pandemic vaccination program and so understanding these views and addressing any misunderstandings, may support gatekeepers to act as that linguistic link for their community.

Amongst our participants there was a tendency to talk about community and religious leaders as potential gatekeepers into the community, however previously it has been suggested that young people can fulfil this bridging role (Marlowe \& Bogen, 2015). Given their linguistic capital and digital literacies, they have the potential to be cultural brokers and links between decision makers and the community. Their role could extend to community settings, but also within their own multigenerational household. The challenge is that, despite the resources that young people bring, experts often miss them (Ingamells \& Westoby, 2008). This issue appeared to play out during the first year of the pandemic, when focus seemed to be on the use of mass media and traditional channels of communication. However, there was a shift and a greater recognition of the role of younger influencers during the second year of the COVID-19 
pandemic by the Australian Government, with an increase in the use of social media and other platforms including TikTok. Recognizing and supporting young people to be gatekeepers in their communities is critical especially in situations where parents and family members do not speak the host society's language. In these situations, the young people from CaLD backgrounds may represent the primary or only linguistic link with the host society. For instance, Mitchell et al. presented two case scenarios which highlighted the role that young people played in being the mediator between their respective communities and external forms of support (Tom, Katharine, Nick, Wei, \& Katie, 2008). Firstly, the case of young El Salvadorians who supported the response to multiple natural hazards (earthquakes, hurricanes, and landslides) and Vietnamese youth reacting to Hurricane Katrina. Mitchell goes on to highlight that young people not only play an important role in providing a bridge to their families and communities, but also have the potential to be informants within informal and formal risk communication networks (Lori, 2008; Tom et al., 2008). Parker and Handmer have even gone as far as to suggest that unofficial or information communication networks can be greatly improved by tapping into young people (Parker \& Handmer, 1998). However, this has yet to be properly explored.

As part of the COVID-19 vaccine program roll-out, some local government areas introduced vaccine ambassadors or champions to support vaccine confidence and increase uptake. These ambassadors are volunteers or paid employees who provide education about vaccine efficacy by sharing personal reasons for confidence in the vaccine based on real-life experience. In some settings, the role was aimed at those with lived experiences including of taking the vaccine, of being homeless, or being part of a racial minority group, with the aim to promote two-way communication and opportunities for concerns to be raised and addressed. Given the nature of the role, job descriptions were put out which highlighted that the ambassador would attend training, provide outreach via personal interactions and social media, facilitate two-way communication, and attend vaccine events and mobile vaccine units to provide peer support and liaison between the public health officials and the community. In one example job description, it was suggested that the salary range should "commensurate with the importance of the position in the community and the skills required to be effective". While studies looking at the effectiveness of these programs on communities have yet to emerge, there are distinct advantages of these formal programs which need to be acknowledged. Firstly, that in some instances these ambassadors receive training on how to build confidence around COVID-19 vaccines, and they are supported with the resources to facilitate discussions about the vaccines. Secondly (and perhaps most importantly), their time is properly acknowledged and paid. Research is needed to establish the usefulness of these roles, as well as the perceptions of those who participated as ambassadors, as the model may be useful in other health promotion settings with established disparities within communities or in situations of natural disasters.

\section{Limitations}

The study team acknowledges that CaLD communities are distinct yet heterogenous groups with unique health delivery needs (Komaric, Bedford, \& van Driel, 2012). Efforts were therefore made to ensure stakeholders were recruited across a range of different CaLD communities, however, it should be 
acknowledged that we could not include participants from all the different migrant groups in Australia. The following are noted as limitations for this work: (1) interviews were only undertaken with a select group of participants, so the possibility of other important themes emerging cannot be ruled out; (2) the use of snowball recruitment may have also reduced the range of opinions amassed from participants; and (3) specific details regarding the participants' role was also not collected.

\section{Conclusion}

It is critical that in preparing and responding to pandemics and other disasters, that there is recognition of the role of community leaders and other gatekeepers and that resources, training and opportunities for financial remuneration are identified to enhance and sustain their involvement. Future pandemic plans must include communication strategies which acknowledge the role of different channels and actors. Researchers and policy makers must work with gatekeepers to improve access to vital information about the community and to develop effective policy for the communities they serve.

\section{Declarations}

Competing interests: None

Ethics approval and consent to participate: All of the methods used in this study were performed in accordance with the relevant guidelines, outlined by The National Statement on Ethical Conduct in Human Research, published by the Australian Government. Informed verbal consent was collected from all participants.

Availability of data and materials: The datasets generated during and/or analysed during the current study are not publicly available due to the sensitive nature of the topic raised during the interviews, but are available from the corresponding author on reasonable request.

Funding: No funding was received.

Acknowledgements: The research team wish to thank the participants for their support of this study.

\section{References}

1. Abdi, I., Murphy, B., \& Seale, H. (2020). Evaluating the health literacy demand and cultural appropriateness of online immunisation information available to refugee and migrant communities in Australia. Vaccine.

2. Agada, J. (1999). Inner-city gatekeepers: An exploratory survey of their information use environment. 5O(1), 74-85. doi:https://doi.org/10.1002/(SICI)1097-4571(1999)50:1<74::AID-ASI9>3.0.CO;2-F

3. Anderson, K. A., Maile, J. J., \& Fisher, L. G. (2010). The Healing Tonic: A Pilot Study of the Perceived Ability and Potential of Bartenders (Vol. 18): Australian Military Medical Association Inc. 
4. Australian Goverment. (2021). COVID-19 Vaccination Program: Culturally and Linguistically Diverse Communities Implementation Plan. Retrieved from

5. Bozkurt, A., \& Gürsakal, N. (2017). Identifying gatekeepers in online learning networks. World Journal on Educational Technology: Current Issues, 9, 75-88.

6. Buchanan, S., Jardine, C., \& Ruthven, I. (2019). Information behaviors in disadvantaged and dependent circumstances and the role of information intermediaries. Journal of the Association for Information Science and Technology, 70(2), 117-129. doi:https://doi.org/10.1002/asi.24110

7. Chen, W., \& Choi, A. S. K. (2011). Internet and social support among Chinese migrants in Singapore. New Media \& Society, 13(7), 1067-1084.

8. Cohen, S., Brissette, I., Skoner, D., \& Doyle, W. (2000). Social Integration and Health: The Case of the Common Cold. Journal of Social Structure, 1.

9. Florio, E. R., \& Raschko, R. (1998). The gatekeeper model: implications for social policy. J Aging Soc Policy, 10(1), 37-55. doi:10.1300/j031v10n01_03

10. Henderson, S., \& Kendall, E. (2011). Culturally and linguistically diverse peoples' knowledge of accessibility and utilisation of health services: exploring the need for improvement in health service delivery \%J Australian Journal of Primary Health. 17(2), 195-201.

11. Ingamells, A., \& Westoby, P. (2008). Working with young people from refugee backgrounds in Australia. European Journal of Social Work, 11(2), 161-173. doi:10.1080/13691450701532180

12. Isaac, M., Elias, B., Katz, L. Y., Belik, S.-L., Deane, F. P., Enns, M. W., \& Sareen, J. (2009). Gatekeeper Training as a Preventative Intervention for Suicide: A Systematic Review. The Canadian Journal of Psychiatry, 54(4), 260-268. doi:10.1177/070674370905400407

13. Jessup, R. L., Osborne, R. H., Beauchamp, A., Bourne, A., \& Buchbinder, R. (2017). Health literacy of recently hospitalised patients: a cross-sectional survey using the Health Literacy Questionnaire (HLQ). BMC Health Services Research, 17(1), 52.

14. Keith, A. A., Jeffrey, J. M., \& Lynette, G. F. The Healing Tonic: A Pilot Study of the Perceived Ability and Potential of Bartenders. Journal of Military and Veterans' Health. doi:10.3316/informit.894569931254541

15. Komaric, N., Bedford, S., \& van Driel, M. L. (2012). Two sides of the coin: patient and provider perceptions of health care delivery to patients from culturally and linguistically diverse backgrounds. BMC Health Services Research, 12(1), 322.

16. Lipson, S. K., Speer, N., Brunwasser, S., Hahn, E., \& Eisenberg, D. (2014). Gatekeeper Training and Access to Mental Health Care at Universities and Colleges. Journal of Adolescent Health, 55(5), 612619. doi:https://doi.org/10.1016/j.jadohealth.2014.05.009

17. Lori, P. (2008). Children and Disasters: Understanding Vulnerability, Developing Capacities, and Promoting Resilience \&\#x2014; An Introduction. Children, Youth and Environments, 18(1), 1-29.

18. Lu, Y. (2007). The human in human information acquisition: Understanding gatekeeping and proposing new directions in scholarship. Library \& Information Science Research, 29(1), 103-123. 
19. Marlowe, J., \& Bogen, R. (2015). Young people from refugee backgrounds as a resource for disaster risk reduction. International Journal of Disaster Risk Reduction, 14, 125-131.

doi:https://doi.org/10.1016/j.ijdrr.2015.06.013

20. Mileti, D. S., \& Darlington, J. D. (2014). The Role of Searching in Shaping Reactions to Earthquake Risk Information. Social Problems, 44, 89-103.

21. Ogie, R. I., \& Perez, P. (2020). Collaborative translation of emergency messages (Co-TEM): An Australian case study. International journal of disaster risk reduction : IJDRR, 50, 101920-101920. doi:10.1016/j.ijdrr.2020.101920

22. Parker, D. J., \& Handmer, J. W. (1998). The Role of Unofficial Flood Warning Systems. Journal of Contingencies and Crisis Management, 6(1), 45-60. doi:https://doi.org/10.1111/1468-5973.00067

23. Richards, L. (2014). Handling Qualitative Data: SAGE Publications.

24. Sarason, I. G., Sarason, B. R., Shearin, E. N., \& Pierce, G. R. (1987). A Brief Measure of Social Support: Practical and Theoretical Implications. Journal of Social and Personal Relationships, 4(4), 497-510. doi:10.1177/0265407587044007

25. Shepherd, J., \& van Vuuren, K. (2014). The Brisbane flood: CALD gatekeepers' risk communication role. Disaster Prevention and Management, 23(4), 469-483.

26. Tierney, K. J. (2019). Disasters: A sociological approach: Wiley.

27. Tom, M., Katharine, H., Nick, H., Wei, C., \& Katie, O. (2008). The Roles of Children and Youth in Communicating Disaster Risk. Children, Youth and Environments, 18(1), 254-279.

28. Tong, A., Sainsbury, P., \& Craig, J. (2007). Consolidated criteria for reporting qualitative research (COREQ): a 32-item checklist for interviews and focus groups. International Journal for Quality in Health Care, 19(6), 349-357. doi:10.1093/intqhc/mzm042

29. Wild, A., Kunstler, B. E., Goodwin, D., SkouterisHelen , Zhang Li , Kufi, M., \& Faduma, M. (2020). Communicating COVID-19 Health Information to Culturally and Linguistically Diverse (CALD) Communities: The Importance of Partnership, Co-design, and Behavioural and Implementation Science. MetaArXiv.

30. Yonemoto, N., Kawashima, Y., Endo, K., \& Yamada, M. (2019). Gatekeeper training for suicidal behaviors: A systematic review. Journal of Affective Disorders, 246, 506-514. doi:https://doi.org/10.1016/j.jad.2018.12.052

\section{Supplementary Files}

This is a list of supplementary files associated with this preprint. Click to download.

- Supplementary1.docx 